\title{
ESTUDO COGNITIVO EM SUJEITOS COM ESQUIZOFRENIA DE UM CENTRO DE ATENDIMENTO PSICOSSOCIAL (CAPS)
}

\author{
COGNITIVE STUDY IN SUBJECTS WITH SCHIZOPHRENIA OF A PSYCHOSOCIAL \\ CARE CENTER (PCC)
}

\section{ESTUDIO COGNITIVO EN SUJETOS CON ESQUIZOFRENIA DE UN CENTRO DE ATENDIMIENTO PSICOSOCIAL (CAPS)}

Eva Teresinha de Oliveira Boff ${ }^{1}$; Ana Júlia Forchesatto²; Marcele Homrich Ravasio ${ }^{3}$

\section{RESUMO}

Esta investigação teve como objetivo identificar os principais déficits cognitivos matemáticos em 17 sujeitos com diagnóstico de esquizofrenia. Estes sujeitos participavam de um grupo terapêutico de um Centro de Atenção Psicossocial (Caps) de um município do Rio Grande do Sul. A perspectiva do Caps é de tratamento e reestabelecimento (Recovery) de fatores cognitivos básicos, que influenciam nas atividades cotidianas e no âmbito familiar e social. Trata-se de uma pesquisa de abordagem qualitativa, descritiva, transversal, com base no instrumento de matemática do Programa Brasil Alfabetizado. Dos resultados obtidos emergiram quatro categorias guiadas pela matriz de análise, as quais indicaram que os sujeitos apresentam déficits cognitivos que podem causar importantes impactos na sua vida cotidiana. Eles apresentaram dificuldades em todas as categorias, porém o maior déficit foi revelado na Categoria IV, que envolvia maior grau de complexidade, englobando questões com mais de uma operação matemática, operações inversas e escrita de números com zero intermediário. A realização do teste possibilitou verificar que $62,74 \%$ dos sujeitos apresentam capacidade de resolver questões simples, como somar pequenas quantidades e identificar números, no entanto somente $32,35 \%$ deles conseguem resolver questões com mais de uma operação matemática ou de maior complexidade, o que indica baixo índice de autonomia dos sujeitos investigados para solucionar problemas do cotidiano.

PALAVRAS-CHAVE: Educação. Cognição. Matemática. Esquizofrenia

\footnotetext{
${ }^{1}$ Doutora em Educação em Ciências - Programa Química da Vida e Saúde da Universidade Federal do Rio Grande do Sul (UFRGS) - Porto Alegre, RS. Professora - Universidade Regional do Noroeste do Rio Grande do Sul (UNIJUI) - Ijuí, RS. E-mail: evaboff@unijui.edu.br

2 Mestre em Atenção Integral em Saúde - Universidade Regional do Noroeste do Rio Grande do Sul (UNIJUI), Ijuí, RS. Professora de Educação Básica - EMEI Anna Zamarchi Coldebella, Semed - Concórdia, SC - Brasil E-mail: bioajf88@gmail.com

${ }^{3}$ Doutora em Educação - UFRGS. Pós-doutoranda em Educação nas Ciências na Universidade do Noroeste do Estado do Rio Grande do Sul (UNIJUI). Docente do Mestrado Profissional em Educação Profissional e Tecnológica (PROFEPT) - Instituto Federal Farroupilha - Campus Santo Ângelo. E-mail:

marcele.ravasio@iffarroupilha.edu.br
}

Submetido em: 28/06/2018 - Aceito em: 20/12/2019

(C) ETD- Educação Temática Digital Campinas, SP $\quad$ v.22 n.1 $\quad$ p.253-274 jan./mar.2020 


\section{ABSTRACT}

This research aims at identifying the main mathematical cognition deficits in 17 subjects diagnosed with schizophrenia. These subjects participated in a Psychosocial Care Center (Caps) therapeutic group from a city of Rio Grande do Sul. The Caps perspective is based on treatment and recovery of basic cognition factors, which influence the daily activities, the family social environment. This is a research of qualitative, descriptive, crosssectional approach based on the mathematical instrument of the Literacy Brazilian Program. It emerged from the obtained results four categories guided by the analysis matrix, which indicates that the subjects have cognitive deficits, which could cause significant impacts on their daily life. They presented difficulties in all categories, but the biggest deficit was revealed in the Category IV, which involved a higher degree of complexity, encompassing questions with more than one mathematical operation, inverse operations and number writing with intermediate zero. It was possible to verify after the test performed that $62.74 \%$ of the subjects have the ability to solve simple questions, such as adding small quantities and identifying numbers, however only $32.35 \%$ $f$ the subjects could solve questions with more than one mathematical operation or higher complexity, which indicates low autonomy index regarding the subjects investigated to solve daily problems.

KEYWORDS: Education. Cognition. Mathematics. Schizophrenia.

\section{RESUMEN}

La investigación tuvo como objetivo identificar los principales déficits cognitivos matemáticos en 17 sujetos con diagnóstico de esquizofrenia (edad promedio 50 años). Estos sujetos participaban de un grupo terapéutico de un centro de Atención Psicosocial (Caps) de un municipio de Rio Grande do Sul. La perspectiva del Caps es de tratamiento y restablecimiento (Recovery) de factores cognitivos básicos, que influencian en las actividades cotidianas y en el ámbito familiar y social. Se trata de una investigación de enfoque cualitativo, descriptivo, transversal, con base en el instrumento de matemáticas del programa Brasil Alfabetizado. De los resultados obtenidos surgieron cuatro categorías guiadas por la matriz de análisis, las cuales indican que los sujetos presentan déficits cognitivos que pueden causar importantes impactos en su vida cotidiana. Ellos presentaron dificultades en todas las categorías, sin embargo, el mayor déficit fue revelado en la categoría cuatro (IV), la cual envolvía mayor grado de complejidad, englobando cuestiones con más de una operación matemática, operaciones inversas y escrito de números con cero intermedio. La realización de esta prueba posibilito verificar que $62,74 \%$ de los sujetos presentaban capacidad de resolver cuestiones simples, como sumar pequeñas cantidades e identificar números, no obstante, solamente el 32,35\% de los sujetos consiguieron resolver cuestiones con más de una operación matemática de mayor complejidad, lo que indica bajo índice de autonomía de los sujetos estudiados para solucionar problemas de lo cotidiano.

PALABRAS CLAVE: Educación. Cognición. Matemáticas. La esquizofrenia. 


\section{INTRODUÇÃO}

Esta pesquisa foi realizada em um Centro de Atenção Psicossocial (Caps) de um munícipio do interior do Rio Grande do Sul que acolhe sujeitos com diagnóstico de esquizofrenia. A escolha deste local se deu por tratar-se de um espaço que busca, além do tratamento da doença, o aprimoramento de estratégias de ensino que potencializem o desenvolvimento dos processos cognitivos em uma perspectiva de inclusão desses sujeitos na sociedade. A esquizofrenia é uma das graves doenças mentais, apresentando maior frequência e ocorrência de fatores limitantes e incapacitantes (SÁNCHEZ, 2012; HÜBNER; KAIROF MARI; COELHO, 2018), impedindo o sujeito de ter uma vida social adequada. De acordo com Giacon e Galera (2013), a esquizofrenia é um dos principais problemas de saúde mental, exigindo considerável investimento do sistema de saúde, cujos sinais e sintomas variam e incluem alterações na percepção, na emoção, na cognição, no pensamento e no comportamento. Para os epidemiologistas da esquizofrenia, segundo Plaza (2010), ela é uma doença universal comum, presente em todas as culturas e áreas geográficas, sem distinção de raça, sexo ou nível socioeconômico. Afeta $1 \%$ da população do mundo a cada ano, sendo diagnosticados entre 2 e 4 novos casos por 10.000 habitantes entre 15 e 54 anos (HÜBNER; KAIROF MARI; COELHO, 2018). Estima-se que cerca de 45 milhões de pessoas em todo o mundo sofrem de esquizofrenia. A idade de início da doença está entre o final da adolescência e o início da vida adulta, momento em que o cérebro está totalmente desenvolvido e apresentou erros em sua maturação, assim como nos processos de constituição da subjetividade.

Não se pode definir a esquizofrenia num único conceito central e linear. Ela é uma doença intrigante, com parâmetros complexos, que se assemelha a outras formas de adoecimento. $O$ sujeito não consegue viver e integrar-se com ele próprio, tampouco com as demais pessoas da sociedade (MARQUES-TEIXEIRA, 2015). Definir a esquizofrenia é limitar um assunto de alto teor de relevância. A enfermidade pode ser vista como uma psicose crônica idiopática; um conjunto de diferentes doenças com sintomas que se assemelham e se sobrepõem. Sua natureza equivale à multifatorialidade, na qual os fatores genéticos e ambientais parecem estar associados a um aumento no risco de desenvolver a doença (SILVA, 2006). Assim, a esquizofrenia e seu conceito de desagregação mental ou síndrome de dissociação, incide sobre o psiquismo nas formas de pensamento (curso e conteúdo), linguagem falada e escrita, percepções, psicomotricidade e vida afetiva (STERIAN, 2001).

Costa e Peres (2018, p. 128) destacam o conceito de esquizofrenia, proposto por Vygotsly, como sendo a "desintegração da formação conceitual da consciência, ocasionando o prejuízo na percepção da realidade, dos outros e de si mesmo". Um dos sintomas da esquizofrenia, portanto, é o comprometimento do estabelecimento de relações necessárias 
para a formação dos conceitos e outros processos psicológicos, como percepção, memória, atenção, concepção de mundo, dentre outros.

Para Bambo (2010), a desordem mental, em âmbito de pensamento confuso e desorganizado, é a característica mais marcante e, talvez, a mais relevante. É por meio da fala que se consegue perceber se as questões são constituídas de distorções (incoerência na fala), fazendo com que o sintoma seja tão grave a ponto de causar uma alteração substancial na comunicação eficaz. Nos casos menos graves de distorções de pensamento, podem ocorrer as fases prodrômicas ou residuais da esquizofrenia. Esses fenômenos de pensamento incluem, pelo Código Internacional das Doenças - CID (OMS) -, eco do pensamento, inserção do pensamento, roubo do pensamento, percepção delirante, delírios de controle, de influência e de passividade, vozes alucinatórias comentando ou discutindo sobre o doente na terceira pessoa, perturbações do pensamento e sintomas negativos.

Neste sentido, Vaz-Serra et al. (2010), em seu estudo sobre esquizofrenia, relataram que os déficits cognitivos estão presentes na grande maioria dos doentes com esquizofrenia, e parecem ser mais marcados nos domínios da memória verbal, vigilância e atenção, memória de trabalho, quociente intelectual, linguagem e funcionamento executivo. Tais déficits aparentam constituir-se os principais determinantes da funcionalidade dessas pessoas.

Conforme indicam Rocha et al. (2009), a esquizofrenia apresenta déficits neurocognitivos generalizados, principalmente aqueles que derivam do sistema frontal executivo e das estruturas mediais do cérebro (atenção, memória, funções executivas, velocidade psicomotora). Esses déficits conceituais clinicamente revelam-se dissociados da sintomatologia. Tais déficits podem condicionar significativamente a resposta funcional e a qualidade de vida das pessoas portadoras da doença.

Segundo Ferreira Junior et al. (2010), o fator inteligência, na esquizofrenia, pode ser analisado a partir de estudos que utilizam avaliações neurocognitivas, demonstrando alterações de habilidades ou fatores específicos da inteligência, tais como inteligência fluída, conhecimento quantitativo, inteligência cristalizada, leitura e escrita, memória de curto prazo, processamento visual, processamento auditivo, armazenamento e recuo/memória de longo prazo, velocidade de processamento, rapidez de decisão e funcionamento cotidiano do sujeito.

Como a doença manifesta-se tardiamente, embora haja tratamento, há perdas cognitivas e funcionais que são limitantes e persistem ao longo da vida da pessoa. A família e o sujeito com esquizofrenia necessitam reorganizar as rotinas diárias de tratamento, adaptarse à doença e à nova configuração (BRASIL, 2013).

Além dos fatores decorrentes da doença também existem fatores externos que dificultam o desenvolvimento de competências e possibilidades funcionais de recuperação, como o preconceito, o que, consequentemente, dificulta a inclusão social desses indivíduos.

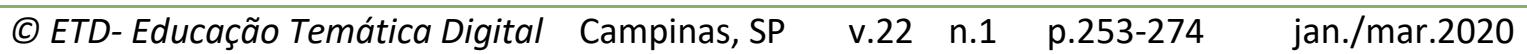


Tais fatores afetam diversas esferas de sua vida, incluindo relações interpessoais, empoderamento sobre a doença, busca de tratamento e autoestima, além de prejudicar no âmbito profissional e econômico, de moradia, de experiências sociais e de vida familiar (MELO et al., 2019). Neste sentido, esta pesquisa denota refletir sobre a importância dessas perdas cognitivas para ajudar no processo de reestabelecimento destes sujeitos.

Considerando-se que os aspectos cognitivos, afetivos e sociais estão, geralmente, comprometidos nos sujeitos com diagnóstico de esquizofrenia, entende-se a necessidade de desenvolver estratégias de ensino que potencializem o desenvolvimento dos processos cognitivos desses indivíduos. Neste sentido, buscou-se, neste artigo, trazer reflexões sobre um processo de investigação relativo às competências de Matemática expressas na Matriz de Referência em Matemática, Leitura e Escrita do Programa Brasil Alfabetizado (BRASIL, 2008a). O uso do teste de matemática justifica-se pela importância do domínio de operações básicas para que os sujeitos possam ter maior autonomia.

\section{METODOLOGIA}

A investigação caracteriza-se como um estudo qualitativo, descritivo e transversal, composto por 17 adultos com diagnóstico de esquizofrenia (Código Internacional de Doenças - CID 20.0-OMS) pertencentes a um grupo de intervenção terapêutica de um Centro de Atenção Psicossocial - Caps. Os critérios de inclusão dos sujeitos da pesquisa foram: ter diagnóstico de Espectro Esquizofrênico, segundo prontuário médico da equipe do Caps, e participar regularmente dos grupos terapêuticos de intervenção (estando em tratamento via Caps). Os sujeitos deste grupo terapêutico possuem certo grau de autonomia (MARTINS, 2002 , p. 202) para realizar as funções cotidianas. Alguns moram sozinhos e outros com a família, mas todos são capazes de se responsabilizarem por si mesmos.

Todos concordaram com a participação da pesquisadora (também professora no Caps) no grupo de intervenção, e aceitaram assinar o Termo de Consentimento Livre e Esclarecido (TCLE). Para assegurar a integridade dos sujeitos aqui referidos e valorizar uma condução ética ${ }^{4}$ durante todo o processo desta pesquisa, foram respeitados os direitos dos indivíduos, levando-se em consideração o que prescreve a Resolução 466/12 do Conselho Nacional de Saúde (BRASIL, 2012).

Este centro de atendimento foi escolhido como campo de pesquisa por realizar maior número de atendimentos em esquizofrenia para adultos na área da Saúde Mental da cidade,

${ }^{4} \mathrm{O}$ projeto de pesquisa obteve parecer favorável à sua execução sob CAAE no 43939315.6.0000.5350, submetido, em 9 de abril de 2015, ao Comitê de Ética em Pesquisa da Universidade Regional do Noroeste do Estado do Rio Grande do Sul (Unijuí).

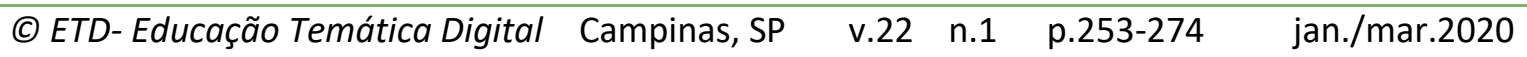


e por se tratar de um espaço que busca, além do tratamento da doença, o aprimoramento de estratégias de ensino que potencializem o desenvolvimento dos processos cognitivos em uma perspectiva de inclusão desses sujeitos na sociedade.

O procedimento de levantamento dos dados desenvolveu-se a partir de entrevistas semiestruturadas, participação dos grupos de intervenção e desenvolvimento de aulas de alfabetização.

Dentre as condições gerais desta amostra, destaca-se a idade média dos participantes, que era em torno dos 50 anos, sendo a maioria homens. Todos os sujeitos do estudo estavam inseridos no CID 20 como portadores de esquizofrenia, e fazem uso da medicação Clozapina de $100 \mathrm{mg}$. Todos participam semanalmente do grupo de intervenção terapêutico. A estrutura do grupo terapêutico abordado na pesquisa é composta por um médico psiquiatra, dois enfermeiros, um técnico de enfermagem, um assistente social e um auxiliar de farmácia, que fazem parte regularmente dos grupos de intervenção.

O instrumento utilizado, chamado Teste Cognitivo de Matemática (BRASIL, 2008a), integra um programa coordenado pelo Ministério da Educação (MEC) em parceria com as Secretarias Estaduais e Municipais de Educação, Instituições de Ensino Superior e outras instituições alfabetizadoras de jovens, adultos e idosos (BRASIL, 2008b). Para a produção do diagnóstico sobre o aprendizado em matemática, há uma matriz de referência baseada nos conhecimentos considerados fundamentais para determinado nível do ensino de Matemática. A matriz de referência apresenta um conjunto limitado de capacidades e conhecimentos passíveis de serem verificados (BRASIL, 2008a). A matriz indica o que é básico e essencial a ser garantido num programa de alfabetização (BRASIL, 2008a). As situações propostas pelo instrumento assemelham-se a atividades do cotidiano, tais como: associar símbolos, realizar contagens, pegar um ônibus e pagar a passagem, e ir ao mercado ou a uma loja comprar um objeto reconhecendo uma etiqueta de preço ou nota de dinheiro. O Teste avalia cinco competências reconhecidas na matriz comentada relacionadas aos conhecimentos de números (realizar contagens, reconhecer os algarismos, ler números, escrever números, comparar números) e cinco competências relacionadas aos conhecimentos de operações (resolver problemas envolvendo: adição ou subtração, multiplicação, divisão, adição e multiplicação associadas, operações de adição e subtração).

Assim, a realização do teste cognitivo básico de matemática em sujeitos com esquizofrenia possibilitou identificar os principais déficits nos desempenhos rotineiros desses sujeitos. Optou-se por este instrumento por se tratar de uma matriz de referência em avaliação no Brasil, abrangendo conhecimentos básicos para pessoas - jovens ou adultas -, assim como efetua avaliação de situações de autonomia. 
A aplicação do teste desenvolveu-se nas aulas de alfabetização pela professora alfabetizadora/pesquisadora. Primeiramente foi organizada a turma para que os sujeitos não visualizassem a resposta dos colegas. Em seguida foram lidas, no máximo, duas vezes as instruções de cada questão e indicada a sua página para a resposta. O tempo de aplicação (entre dois e três minutos) foi controlado para que todos começassem e terminassem juntos, e prosseguia-se para a próxima questão depois de três minutos de pausa. A alfabetizadora/pesquisadora leu as instruções e verificou se os alunos estavam marcando as respostas no local indicado.

No Teste Cognitivo de Matemática utilizou-se 10 competências e 16 descritores, conforme expresso no Quadro 1. Na parte dos números mostra-se o conhecimento em relação às noções fundamentais e níveis de dificuldade quanto à leitura, relação do maior para o menor número, escrita, contagens, suas representações com cédulas em papel e quantidades de dinheiro, interpretação e compreensão para tomadas de decisão. Na parte das operações, considera-se a compreensão das operações fundamentais: adição, subtração, multiplicação e divisão, elaboração e cálculo mental, capacidade de decisão, execução, operar procedimentos padronizados, reconhecimento, habilidade de resolver cálculos necessários com números decimais com vírgula e capacidade de estratégia pessoal de cálculos mais elaborados. 
QUADRO 1

Noções básicas e elementares de matemática presentes na Matriz de Referência

\begin{tabular}{|c|c|c|}
\hline Conhecimentos & Competências & Descritores \\
\hline \multirow{9}{*}{ Números } & \multirow{3}{*}{ C1. Realizar contagens } & D01. Realizar contagens de pequenas quantidades \\
\hline & & $\begin{array}{l}\text { D02. Realizar contagens de quantidades maiores } \\
\text { (por agrupamento ou outras estratégias) }\end{array}$ \\
\hline & & $\begin{array}{l}\text { D03. Realizar contagem de quantias em dinheiro } \\
\text { com cédulas e moedas }\end{array}$ \\
\hline & $\begin{array}{l}\text { C2. Reconhecer os } \\
\text { algarismos }\end{array}$ & D04. Associar o algarismo ao seu nome \\
\hline & \multirow[t]{2}{*}{ C3. Ler Números } & D05. Ler números naturais de 2,3 ou 4 algarismos \\
\hline & & $\begin{array}{l}\text { D06. Ler números decimais que expressam valor } \\
\text { monetário }\end{array}$ \\
\hline & C4. Escrever Números & D07.Escrever números de 2, 3 ou 4 algarismos \\
\hline & \multirow[t]{2}{*}{ C5. Comparar Números } & $\begin{array}{l}\text { D08. Comparar números naturais (escritos no } \\
\text { sistema de numeração decimal) }\end{array}$ \\
\hline & & $\begin{array}{l}\text { D09. Comparar números decimais que expressam } \\
\text { valor monetário }\end{array}$ \\
\hline \multirow[t]{7}{*}{ Operações } & \multirow{3}{*}{$\begin{array}{l}\text { C6. Resolver problemas } \\
\text { envolvendo Adição ou } \\
\text { Subtração }\end{array}$} & $\begin{array}{l}\text { D10. Resolver problemas envolvendo adição ou } \\
\text { subtração de números naturais ou de quantias em } \\
\text { dinheiro por qualquer método, para a produção de } \\
\text { uma resposta aproximada }\end{array}$ \\
\hline & & $\begin{array}{l}\text { D11. Resolver problemas envolvendo adição de } \\
\text { números naturais ou de quantias em dinheiro por } \\
\text { qualquer método, para a produção de uma resposta } \\
\text { exata }\end{array}$ \\
\hline & & $\begin{array}{l}\text { D12. Resolver problemas envolvendo subtração de } \\
\text { números naturais ou de quantias em dinheiro por } \\
\text { qualquer método, para a produção de uma resposta } \\
\text { exata }\end{array}$ \\
\hline & $\begin{array}{l}\text { C7. Resolver problemas } \\
\text { envolvendo } \\
\text { Multiplicação }\end{array}$ & $\begin{array}{l}\text { D13. Resolver problemas envolvendo multiplicação, } \\
\text { com a ideia de adição repetida, em que o } \\
\text { multiplicador é um número menor do que } 10\end{array}$ \\
\hline & $\begin{array}{l}\text { C8. Resolver problemas } \\
\text { envolvendo Divisão }\end{array}$ & $\begin{array}{l}\text { D14. Resolver problemas envolvendo divisão com } \\
\text { a ideia de partilha, em que o divisor é um número } \\
\text { natural menor que } 10\end{array}$ \\
\hline & $\begin{array}{l}\text { C9. Resolver problemas } \\
\text { envolvendo Adição e } \\
\text { Multiplicação Associadas }\end{array}$ & $\begin{array}{l}\text { D15. Resolver problemas envolvendo a adição de } \\
\text { produtos de números naturais (menores que 10) ou } \\
\text { de um número natural (menor que 10) multiplicado } \\
\text { por um decimal, representando quantias em } \\
\text { dinheiro }\end{array}$ \\
\hline & $\begin{array}{l}\text { C10. Resolver problemas } \\
\text { envolvendo Operações } \\
\text { de Adição e Subtração }\end{array}$ & $\begin{array}{l}\text { D16. Resolver problemas envolvendo uma sucessão } \\
\text { de operações de adição e subtração }\end{array}$ \\
\hline
\end{tabular}

Fonte: BRASIL, 2008a, p. 10. 
Com o intuito de facilitar a análise dos resultados, foram organizadas quatro categorias considerando o grau de dificuldade, posto que a categoria I inicia com questões simples e a categoria IV apresenta questões mais complexas, conforme expresso a seguir:

Categoria I - pequenas quantidades: associação de algarismo ao nome; ler números decimais que expressam valor monetário; ler preços; escrever números de 2, 3 ou 4 algarismos, não envolvendo algarismo zero; escrever números de três algarismos com uma dificuldade especial colocando o zero no meio; comparar números naturais escritos no sistema decimal.

Categoria II - problemas com uma operação: ler números naturais de 2, 3 ou 4 algarismos (numeração oral e escrita); ler números naturais de 2, 3 ou 4 algarismos (avalia a capacidade de registro); comparar números decimais que expressam valor monetário, comparar números com vírgula com duas casas decimais que expressam centavos; resolver problemas envolvendo adição de números naturais, quantias em dinheiro por qualquer abordagem com resposta exata; avaliar se o aluno subtrai pequenas quantias e realiza cálculo mental; verificar se o aluno resolve por multiplicação ou adição repetida em que o multiplicador é um número natural menor de 10; avaliar o conhecimento que o aluno tem sobre multiplicação de parcelas iguais envolvendo quantias de dinheiro em centavos; resolução por divisão ou ideia de partilha envolvendo divisor de número natural menor que 10.

Categoria III - problemas com mais de uma operação: escrever números de 2, 3 ou 4 algarismos diferentes de zero com quantias em dinheiro e resposta exata em relação à subtração; resolver problemas envolvendo adição de produtos naturais (menores de 10) ou adição de números naturais (menores de 10 ) vezes um número decimal, representando quantias em dinheiro, sendo possível efetuar a equação com a adição de várias parcelas iguais.

Categoria IV - problemas com operações inversas e escrita de números com zero intermediário: resolver problemas envolvendo adição e subtração de números naturais abrangendo cédulas de dinheiro, simulando uma compra numa venda e um resultado com a quantidade de dinheiro em mãos, exigindo o troco. Produzir uma resposta aproximada; resolver por qualquer método envolvendo divisão ou partilha com divisor natural menor de 10; resolver problemas envolvendo a sucessão de operações de adição e subtração; abranger números naturais menores de 30 que são enunciados, e o aluno precisa efetuar as operações em ordem de narração.

Deste modo, a categoria I contém em si conhecimentos de leitura e escrita de números, assim como de reconhecer algarismos e operações simples. A categoria II envolve problemas de conhecimento de números e uma operação matemática. A categoria III abrange 
problemas com mais de uma operação, e a Categoria IV problemas com operações inversas e escrita de números com zero intermediário.

Os resultados sobre os déficits cognitivos de matemática, realizados com o grupo terapêutico de um Caps, estão expressos nos quadros 2, 3, 4 e 5, com indicação do total de erros e acertos por questão. As questões que não foram respondidas foram incluídas no total de erros, uma vez que indicam que os sujeitos não responderam por não ter conhecimento. Trata-se de um teste realizado no Brasil inteiro pelo Programa Brasil Alfabetizado (PBA), que visa a alfabetizar jovens, adultos e idosos. Objetiva, ainda, diagnosticar o nível de alfabetização de alunos que já frequentaram e não se alfabetizaram ou nunca frequentaram a escola de maneira regular.

A análise teve como base as compreensões da teoria histórico cultural com suas bases em Vygotsky (1994, 2000, 2013), o qual discute sobre a importância das interações sociais para o desenvolvimento das funções mentais superiores e a construção de aprendizagem em crianças, adolescentes e sujeitos com esquizofrenia.

\section{RESULTADOS E DISCUSSÃO}

Neste artigo optou-se pela análise dos resultados do teste cognitivo de matemática presente na matriz de referência em avaliação no Brasil, por se tratar de instrumento que abrange conhecimentos básicos para qualquer pessoa - jovem ou adulta - e avalia situações de autonomia. Não inclui todas as capacidades, mas indica aspectos essenciais a serem garantidos ao indivíduo com diagnóstico de esquizofrenia.

O teste cognitivo básico de matemática dos pacientes com esquizofrenia ajudou a identificar os principais déficits que implicam desempenho de situações rotineiras, cujos conhecimentos básicos podem melhorar a qualidade de vida do sujeito e de sua família, bem como contribuir no controle do surto da doença, torná-la estabilizada, ajudar na integração social após o aparecimento da doença e cooperar na adesão ao tratamento.

As questões, descritores, número de acertos e erros do teste estão indicados nos Quadros 2, 3, 4 e 5, e foram analisados com base nos argumentos de Vygotsky (1994). O autor investigou os principais déficits cognitivos em sujeitos com esquizofrenia, bem como estabeleceu relações sobre a formação de conceitos em crianças e adolescentes.

Os resultados indicam que os sujeitos investigados apresentam baixa capacidade de formação de conceitos, corroborando as elaborações de Vygotsky, posto que os sujeitos mostraram pouco raciocínio lógico-matemático na medida em que as questões matemáticas foram se complexificando.

Vygotsky (1994) investigou dois aspectos comparativos importantes para a deterioração do pensamento na esquizofrenia e no desenvolvimento do pensamento em crianças na idade da puberdade. Sua conclusão foi diferente dos entendimentos de outros

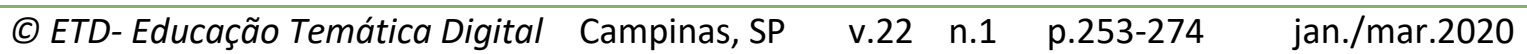


cientistas sobre a questão. Seu estudo abordou o rompimento do pensamento relacionado à hipobulia na dimensão da psicopatologia, e considerou as diferentes fases de desenvolvimento mental para a formação dos verdadeiros conceitos, tais como o pensamento sincrético na dimensão da psicologia infantil e o pensamento por complexos na adolescência. Para o autor, os verdadeiros conceitos formam-se somente na fase final do desenvolvimento, quando existe a capacidade de fazer generalizações e, a partir delas, estabelecer relações complexas.

Vygotsky estruturou, em sua linha de tese, dois sentidos e duas conclusões: - o primeiro é que "o fato mais importante, associado ao pensamento na adolescência, seja a mudança do pensamento por 'complexos' para o pensamento conceitual, uma mudança que não apenas revoluciona o processo intelectual, mas determina a estrutura dinâmica da personalidade e a consciência de si e do ambiente"; - o segundo é que "a deterioração mais importante do pensamento que ocorre na esquizofrenia é um distúrbio, um prejuízo, na função de formação de conceitos" (1994, p. 314).

No processo de desenvolvimento da formação de conceitos existem, no entanto, certas similaridades externas, tanto na esquizofrenia quanto na adolescência, principalmente na transição do pensamento por complexos ao pensamento conceitual (VYGOTSKY, 1994).

Os estudos de Vygotsky mostram que o pensamento de um adolescente segue um caminho oposto ao da esquizofrenia, mas a compreensão do desenvolvimento mental do adolescente poderá contribuir nos entendimentos do pensamento de uma pessoa com esquizofrenia e sua patologia, assim como o entendimento do pensamento de um adulto com esquizofrenia poderá contribuir na compreensão de certos comportamentos adolescentes. Isso indica que ambos têm relação entre pontos de transição distintos, semelhança que se explica pelo termo dementiapraecox. Vygotsky analisou a personalidade, a consciência e o ambiente em si, pois na adolescência ocorre crescimento e desenvolvimento, enquanto na doença existe a regressão desses processos de maneira inversa.

Vygotsky analisa comparativamente a formação dos conceitos na observação de crianças e pessoas com esquizofrenia. O método era o de empregar uma situação em que a pessoa com esquizofrenia deveria formar conceitos artificiais. Baseados em elementos selecionados e coletados, os pacientes deveriam associar as sílabas sem sentido com certos conceitos já bem-definidos. O sujeito era confrontado com um problema de formação de conceitos que somente poderia ser resolvido no laboratório de experimentação e em nenhum outro local. Foi observada, pelo autor, a diminuição da capacidade de formação dos conceitos quando o distúrbio de pensamento era aparente e também nos casos de apenas desordem formal de pensamento. 
Os estudos de Vygotsky corroboram os resultados obtidos pelo teste cognitivo de Matemática, pois, conforme indicado na Categoria I (Quadro 2), 62,74\% dos sujeitos conseguem resolver questões de soluções simples, no entanto o número de acertos diminui significativamente ao comparar com a Categoria IV (Quadro 5), de maior complexidade, com apenas $32,35 \%$ de acertos. Os resultados do teste mostram que os sujeitos têm capacidade de identificar desenhos e dominam alguma técnica de contagem, assim como conseguem sequenciar mentalmente e fazer pequenos agrupamentos. A maioria dos sujeitos sabe realizar contagens simples e ler números, mostrando que estes tiveram algum aprendizado na infância em contato com o domínio cognitivo matemático, o que conduziu à significação desses conceitos.

QUADRO 2. Categoria I

Descrição das questões que envolvem pequenas quantidades e percentual de acertos e erros

\begin{tabular}{|c|c|c|c|c|c|}
\hline \multirow{2}{*}{ Questão } & \multirow{2}{*}{ Descritor da questão } & \multicolumn{2}{|c|}{ Acertos } & \multicolumn{2}{|c|}{ Erros } \\
\hline & & $\mathbf{N}$ & $\%$ & $\mathbf{N}$ & $\%$ \\
\hline $\begin{array}{l}\text { 1) Contar em cada um dos } \\
\text { desenhos que representam um } \\
\text { cesto com } 21 \text { laranjas. As laranjas } \\
\text { estão espalhadas de maneira } \\
\text { irregular. }\end{array}$ & $\begin{array}{l}\text { Contagem de pequenas } \\
\text { quantidades (D01). }\end{array}$ & 15 & 88,24 & 2 & 11,76 \\
\hline $\begin{array}{l}\text { 2) Identificar o número lido } \\
\text { (nove, zero, sete, dois) com a } \\
\text { figura do ônibus que indica esse } \\
\text { número. }\end{array}$ & $\begin{array}{l}\text { Associar números ao seu } \\
\text { nome (D04). }\end{array}$ & 6 & 35,29 & 11 & 64,70 \\
\hline $\begin{array}{l}\text { 3) Escutar o número que indica a } \\
\text { idade e marcar corretamente. }\end{array}$ & $\begin{array}{l}\text { Reconhecer o registro de } \\
\text { um número de dois } \\
\text { algarismos } \\
\text { oralmente (D05). }\end{array}$ & 14 & 82,35 & 3 & 17,65 \\
\hline $\begin{array}{l}\text { 4) Escutar o número e marcar o } \\
\text { correspondente. }\end{array}$ & $\begin{array}{l}\text { Reconhecer o registro de } \\
\text { números com } 4 \text { algarismos } \\
\text { (sem zero), indicado } \\
\text { oralmente (D05). }\end{array}$ & 8 & 47,05 & 9 & 52,94 \\
\hline $\begin{array}{l}\text { 5) Circular ou riscar o desenho da } \\
\text { caixa de bombons ou o seu preço, } \\
\text { ou mesmo escrever de novo o } \\
\text { preço } R \$ 8,60 \text { ao lado do produto. }\end{array}$ & $\begin{array}{l}\text { Ler números decimais que } \\
\text { expressam valor monetário, } \\
\text { ler preços ou registros de } \\
\text { dinheiro (D05). }\end{array}$ & 9 & 52,94 & 8 & 47,06 \\
\hline $\begin{array}{l}\text { 6) Escutar o número e anotar no } \\
\text { papel como se fosse anotar o } \\
\text { número do ônibus. }\end{array}$ & $\begin{array}{l}\text { Esta questão refere-se a } \\
\text { escrever números, } 2,3 \text { e } 4 . \\
\text { Este é um caso simples } \\
\text { (D07). }\end{array}$ & 15 & 88,24 & 2 & 11,76 \\
\hline \multicolumn{2}{|l|}{ TOTAL DE RESPOSTAS } & 64 & 62,74 & $\begin{array}{l}3 \\
5\end{array}$ & 37,26 \\
\hline
\end{tabular}

Fonte: Produzido pelas autoras conforme análise da Matriz. 
Mesmo que a maioria destes resultados indique a capacidade de solução de questões simples, os mesmos mostram que a maior parte dos sujeitos $(64,70 \%)$ não tem autonomia para locomover-se com transportes públicos, como visto na questão número dois (quadro 2), que simulava a figura de quatro ônibus com números diferentes, em que o sujeito deveria reconhecer o número da lotação correspondente ao número lido (9072), pois apenas 35,29\% mostrou reconhecer os algarismos. Esta é uma das questões mais elementares e fundamentais na conquista das demais habilidades matemáticas, na qual o percentual de erros obtido foi superior aos acertos, representando $64,70 \%$ de erros. Ao agruparmos questões incorretas e questões não respondidas, o percentual de respostas não compreendidas chega em torno de $37,26 \%$, sendo um déficit significativo considerando que eram questões simples.

Conforme Plaza (2010), as referências relativas a déficits cognitivos na esquizofrenia não são novas. As primeiras descrições clínicas mostram que estes doentes não somente tinham alucinações e ilusões, mas também alterações no pensamento, atenção e vontade. Sujeitos com esquizofrenia demonstram um déficit cognitivo generalizado, ou seja, eles tendem a ter um desempenho em níveis mais baixos do que controles normais em uma variedade de testes cognitivos. Eles apresentam múltiplos déficits neuropsicológicos em testes de raciocínio conceitual complexo, velocidade psicomotora, memória de aprendizagem nova e incidental e habilidades motoras, sensoriais e perceptuais. As alterações cognitivas seletivas mais proeminentes na esquizofrenia incluem déficits em atenção, memória e resolução de problemas (SILVA, 2006). Na medida em que as questões foram se complexificando, houve diminuição no número de acertos, pois o total de acertos na

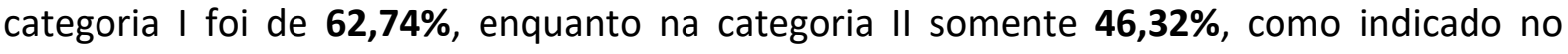
Quadro 3. 


\section{QUADRO 3. Categoria II}

Questões que envolvem problemas com uma operação, acertos e erros

\begin{tabular}{|c|c|c|c|c|c|}
\hline \multirow[t]{2}{*}{ Questão } & \multirow[t]{2}{*}{ Descritor da questão } & \multicolumn{2}{|c|}{ Acertos } & \multicolumn{2}{|l|}{ Erros } \\
\hline & & $\mathbf{N}$ & $\%$ & $\mathbf{N}$ & $\%$ \\
\hline $\begin{array}{l}\text { 7) Circular ou riscar o desenho } \\
\text { que mostra } 52 \text { potes de doce, } \\
\text { ou escrever ao lado de cada um } \\
\text { o número de potes. }\end{array}$ & $\begin{array}{l}\text { Esta questão refere-se a contar } \\
\text { quantidades maiores, e sugere } \\
\text { possibilidades de } \\
\text { agrupamentos (D02). }\end{array}$ & 6 & $\begin{array}{c}35,2 \\
9\end{array}$ & 11 & $\begin{array}{c}64,7 \\
0\end{array}$ \\
\hline $\begin{array}{l}\text { 8) Circular ou riscar o quadro ou } \\
\text { as notas, ou escrever ao lado de } \\
\text { cada quadro a quantia de } \\
\mathrm{R} \$ 48,00 \text {. }\end{array}$ & $\begin{array}{l}\text { Mostra quantias de dinheiro } \\
\text { com cédulas e moedas (D03). }\end{array}$ & 8 & $\begin{array}{c}47,0 \\
6\end{array}$ & 9 & $\begin{array}{c}52,9 \\
4\end{array}$ \\
\hline $\begin{array}{l}\text { 9) Ler o número por extenso e } \\
\text { pedir para o aluno escrever em } \\
\text { algarismos ou por extenso. }\end{array}$ & $\begin{array}{l}\text { Refere-se a escrever números } \\
\text { de } 2,3 \text { ou } 4 \text { algarismos, exceto } \\
\text { zero (D07). }\end{array}$ & 6 & $\begin{array}{c}35,2 \\
9\end{array}$ & 11 & $\begin{array}{c}64,7 \\
0\end{array}$ \\
\hline $\begin{array}{l}\text { 10) Circular ou riscar, ou } \\
\text { escrever o menor número de } \\
\text { refeições por dia indicados em } \\
\text { uma cartela. }\end{array}$ & $\begin{array}{l}\text { Compara números naturais e o } \\
\text { entendimento da } \\
\text { representação escrita, sem ver } \\
\text { as quantidades, do maior para o } \\
\text { menor (D08). }\end{array}$ & 12 & $\begin{array}{c}70,5 \\
9\end{array}$ & 5 & $\begin{array}{c}29,4 \\
1\end{array}$ \\
\hline $\begin{array}{l}\text { 11) Circular ou riscar o desenho } \\
\text { da placa, ou escrever ao lado o } \\
\text { nome da loja ou o preço que ele } \\
\text { julgar mais barato. }\end{array}$ & $\begin{array}{l}\text { Compara números } \\
\text { que expressam } \\
\text { monetário, com dualor } \\
\text { decimais (D09). }\end{array}$ & 9 & $\begin{array}{l}52,9 \\
4\end{array}$ & 8 & $\begin{array}{l}47,0 \\
5\end{array}$ \\
\hline $\begin{array}{l}\text { 12) Circular ou riscar a placa, ou } \\
\text { escrever a soma de dois itens } \\
\text { comprados. }\end{array}$ & $\begin{array}{l}\text { Resolve problemas envolvendo } \\
\text { uma adição de números } \\
\text { naturais ou quantias em } \\
\text { dinheiro (D11). }\end{array}$ & 9 & $\begin{array}{c}52,9 \\
4\end{array}$ & 8 & $\begin{array}{c}47,0 \\
5\end{array}$ \\
\hline $\begin{array}{l}\text { 13) Riscar ou circular a placa, ou } \\
\text { escrever a resposta indicando o } \\
\text { total de convites em relação ao } \\
\text { número de pessoas. }\end{array}$ & $\begin{array}{l}\text { Resolve problemas envolvendo } \\
\text { abstração de números naturais } \\
\text { ou de quantias de dinheiro } \\
\text { (D12). }\end{array}$ & 8 & $\begin{array}{c}47,0 \\
5\end{array}$ & 9 & $\begin{array}{c}52,9 \\
4\end{array}$ \\
\hline $\begin{array}{l}\text { 14) Circular ou riscar a placa, ou } \\
\text { escrever a resposta. }\end{array}$ & $\begin{array}{l}\text { Resolve problemas envolvendo } \\
\text { uma subtração de números } \\
\text { naturais ou de quantias de } \\
\text { dinheiro para uma resposta } \\
\text { exata (D12). }\end{array}$ & 5 & $\begin{array}{c}29,4 \\
1\end{array}$ & 12 & $\begin{array}{c}70,5 \\
9\end{array}$ \\
\hline TOT & & 63 & $\begin{array}{c}46,3 \\
2\end{array}$ & 73 & $\begin{array}{c}53,6 \\
8\end{array}$ \\
\hline
\end{tabular}

Fonte: Produzido pelas autoras a partir da análise da Matriz.

A categoria II refere-se aos descritores em relação a Números e Operações. A questão 14, que envolve subtração, indicou maior percentagem de erros, mostrando mais fragilidade para realizar operações de subtração $(29,41 \%)$ do que de adição $(52,94 \%)$. Já as questões que envolvem comparação de números obtiveram maior número de acertos, como nas questões 10 e 11 , com $70,59 \%$ e $52,94 \%$ de acertos respectivamente. 
Os resultados confirmam os estudos de Vygotsky (1994), ao verificar-se que o pensamento da pessoa com esquizofrenia não permite o estabelecimento de relações complexas, como verificado nas questões matemáticas com maior nível de complexidade. 0 autor parte do princípio de que há semelhanças e similaridades em características fundamentais básicas também no processo de pensamento de uma criança em relação a um sujeito com esquizofrenia. $O$ dano se faz na formação do conceito que regressa o nível de pensamento do sujeito com esquizofrenia à formação de pensamentos por complexos. Os conceitos formados previamente são utilizados de modo automático, levando à complexidade da formação de novos conceitos, tornando-se extremamente difícil sua assimilação para a pessoa com esquizofrenia. Isso deriva que os vários estágios genéticos do pensamento por complexo se estabeleçam no limite psicológico na avaliação do grau de rompimento dessa regressão. Assim, a falha estaria na sua expressão da comparação do pensamento desordenado com as formas filogenéticas anteriores a esse pensamento, que é usualmente baseado na ausência de conceitos de pensamento.

Esta falha encontra expressão no fato de que a comparação do pensamento desordenado com as formas filogeneticamente anteriores de pensamento é usualmente feita com base na ausência de conceitos no pensamento. Esta comparação, baseada num critério negativo é errada porque ela trata como formas de pensamento aproximadamente equivalentes que, do ponto de vista positivo, não tem nada em comum uma com a outra (VYGOTSKY, 1994, p. 316).

Vygotsky (1994) destaca que Volkelt, ao realizar estudos sobre o pensamento das aranhas, fazia a comparação errônea da teoria de pensamento, pois comparava o pensamento de um sujeito com esquizofrenia ao dos povos primitivos, dos sonhos, ou do processo intelectual de animais inferiores, como a aranha, que, por meio de sua consciência seletiva, não percebe as situações e sensações isoladas, mas as emoções condicionadas na totalidade. Vygotsky afirma que "o pensamento associativo dos pacientes com esquizofrenia difere do pensamento de uma pessoa normal", mas não corresponde ao pensamento de animais inferiores (VYGOTSKY, 1994, p. 317). O sujeito com esquizofrenia tem dificuldades em fazer generalizações para evoluir na formação dos verdadeiros conceitos. O Quadro 4 mostra a pouca capacidade de resolução de operações mais complexas que dependem do uso de mais de uma operação, o que indica que não houve a formação do conceito. 
QUADRO 4. Categoria III

Questões onde os problemas aparecem com mais de uma operação

\begin{tabular}{|c|c|c|c|c|c|}
\hline \multirow[t]{2}{*}{ Questão } & \multirow[t]{2}{*}{ Descritor da questão } & \multicolumn{2}{|c|}{ Acertos } & \multicolumn{2}{|c|}{ Erros } \\
\hline & & $\mathbf{N}$ & $\%$ & $\mathbf{N}$ & $\%$ \\
\hline $\begin{array}{l}\text { 15) Circular ou riscar o } \\
\text { cartaz, ou escrever o preço } \\
\text { de uma etiqueta contendo } \\
\text { vírgula e duas casas } \\
\text { decimais. }\end{array}$ & $\begin{array}{l}\text { Avaliar a capacidade de ler } \\
\text { preços e quantias de } \\
\text { dinheiro (D05). }\end{array}$ & 11 & 64,70 & 6 & 35,29 \\
\hline $\begin{array}{l}\text { 16) Riscar no quadro que } \\
\text { tem o valor em dinheiro, que } \\
\text { dá para comprar duas blusas } \\
\text { e que sobre menos troco. }\end{array}$ & $\begin{array}{l}\text { Envolver cálculo de adição e } \\
\text { subtração de números } \\
\text { naturais (D05). }\end{array}$ & 5 & 29,41 & 12 & 70,29 \\
\hline $\begin{array}{l}\text { 17) Reconhecer o preço de } \\
\text { um panfleto de mercado } \\
\text { para a compra de laranjas. }\end{array}$ & $\begin{array}{l}\text { Dá ideia de adição repetida. } \\
\text { Avalia a multiplicação com } \\
\text { soma de parcelas iguais } \\
\text { (D13). }\end{array}$ & 6 & 35,29 & 11 & 64,70 \\
\hline $\begin{array}{l}\text { 18) Utilizar uma lista de } \\
\text { compras e seus preços e } \\
\text { etiquetas em um } \\
\text { supermercado. }\end{array}$ & $\begin{array}{lrr}\text { Resolver } & \text { problemas } & \text { que } \\
\text { envolvam } & \text { adição } & \text { e } \\
\text { multiplicação } & \text { associados } \\
\text { (D15) } & & \end{array}$ & 6 & 35,29 & 11 & 64,70 \\
\hline $\begin{array}{l}\text { 19) Circular ou riscar a placa } \\
\text { com o valor de passagem de } \\
\text { ônibus ou escrever a } \\
\text { resposta. }\end{array}$ & 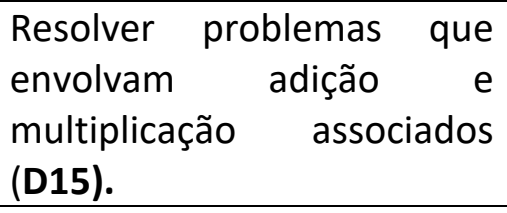 & 6 & 35,29 & 11 & 64,70 \\
\hline $\begin{array}{l}\text { 20) Calcular o valor do troco } \\
\text { a receber no pagamento de } \\
\text { duas contas de água e luz. }\end{array}$ & $\begin{array}{l}\text { Resolver } \\
\text { envolvendo uma sucessão } \\
\text { de operações de adição e } \\
\text { subtração (D16) }\end{array}$ & 6 & 35,29 & 11 & 64,70 \\
\hline \multicolumn{2}{|l|}{ TOTAL DE RESPOSTAS } & 40 & 39,22 & 62 & 60,78 \\
\hline
\end{tabular}

Fonte: Produzido pelas autoras a partir da análise da Matriz.

A categoria III apresenta resultados com maiores acertos na questão 15, indicando um percentual de $64,70 \%$ de acertos, demonstrando capacidade de ler números. As problematizações 17, 18, 19 e 20, porém, apresentam índices significativos de erros. Estas questões avaliam a possibilidade de o sujeito resolver problemas envolvendo multiplicação, adição e multiplicação associadas e operações de adição e subtração.

Na questão número 16 simulou-se uma compra de duas blusas em que havia duas etiquetas com o preço; o sujeito deveria marcar nas opções em que as cédulas equivaliam com o preço. Nessa questão promove-se uma estratégia de cálculo aproximado. Nela, houve baixo número de acertos, o que indica dificuldades possivelmente de contagem ou reconhecimento das cédulas. Vygotsky também observou, em seus estudos, resultados 
semelhantes, e afirma que "as palavras do paciente com esquizofrenia coincidem com as nossas em sua relação com os objetos, mas não em seus significados" (1994, p. 319).

Esse problema se assemelha a situações do cotidiano em que é preciso saber qual é a menor quantidade de dinheiro necessária para efetuar uma determinada compra. Nessas situações, as pessoas têm que "pensar rápido", efetuando cálculos mentais para encontrar um resultado que se aproxime do total a ser pago (BRASIL, 2008c, p. 15).

As questões desta categoria trazem latente o tema do uso da autonomia e da educação permanente com papel importante na reabilitação do sujeito. Conforme salienta Paulo Freire,

$\mathrm{O}$ ato de cozinhar (...) supõe alguns saberes concernentes ao uso do fogão, como acendê-lo, como equilibrar para mais, para menos a chama, como lidar com certos riscos mesmo que remotos de incêndio, como harmonizar diferentes temperos numa síntese gostosa e atraente. A prática de cozinhar vai preparando o novato, ratificando alguns daqueles saberes, retificando outros, e vai possibilitando que ele vire cozinheiro (1996-2002, p. 12).

O mesmo acontece na questão número 19, quando a instrução é pegar um ônibus em que a tarifa de passagem é $R \$ 1,70$. Nesta situação simula-se pegar o transporte do dia e pagar a passagem para cinco pessoas. Para responder esse tipo de questão o sujeito precisa realizar operações numéricas, planejar e reconhecer as cédulas de dinheiro. Esse tipo de situação acontece todos os dias na vida dessas pessoas, porém o percentual de acertos foi baixo $(35,29 \%)$.

Já na questão número 20 simula-se o pagamento de duas contas: uma de água e outra de luz elétrica. Neste tipo de resolução o aluno precisa saber a quantidade de dinheiro que dispõe, quanto irá sobrar e calcular o troco. Essa situação mostra uma questão de autonomia, pois muitos dos entrevistados moram sozinhos, e demostrou também que apenas $35,29 \%$ das pessoas responderam corretamente.

Por ser uma doença multi-heterogênea e com vários fatores associados, com sintomas inespecíficos e que diferem de indivíduo para indivíduo, aliados a diagnósticos imprecisos, o sujeito com esquizofrenia não tratado vivencia intenso sofrimento mental. Além dele, a família e, igualmente, as demais pessoas envolvidas, sofrem com o processo da doença. É uma luta para o sujeito com esquizofrenia viver um dia a dia comum numa sociedade que discrimina o "corpo" que não é belo ou com os padrões de beleza condizentes com a cultura que retrata (MATTOS, 2013; AGOSTINI et al., 2013). Nessa perspectiva, Sá (2011) afirma que os déficits cognitivos se tornam uma característica significativa e central dos doentes com esquizofrenia. Isso afeta a qualidade de vida, o funcionamento social e a resposta a programas de reabilitação.

A categoria IV, expressa no Quadro 5, mostra a incapacidade de escrita e raciocínio lógico-matemático, indicando quase que completa dependência na solução de questões básicas fundamentais do cotidiano, com um total de apenas 32,35\% de acertos.

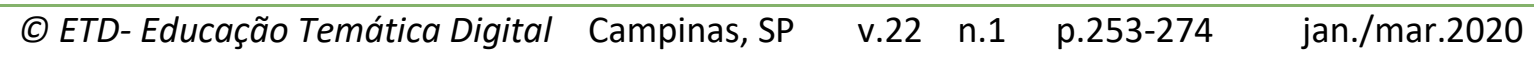




\section{QUADRO 5. Categoria IV}

Compete problemas com operações inversas - escrita de números com zero intermediário

\begin{tabular}{|c|c|c|c|c|c|}
\hline \multirow[t]{2}{*}{ Questão } & \multirow[t]{2}{*}{ Descritor da questão } & \multicolumn{2}{|c|}{ Acertos } & \multicolumn{2}{|c|}{ Erros } \\
\hline & & $\mathbf{N}$ & $\%$ & $\mathbf{N}$ & $\%$ \\
\hline $\begin{array}{l}\text { 21) Escrever um bilhete } \\
\text { colocando o número do } \\
\text { endereço. Escrita por } \\
\text { extenso. }\end{array}$ & $\begin{array}{l}\text { Escrever números de } 2,3 \text { e } 4 \\
\text { algarismos. Aqui se avalia } \\
\text { também o traçado da letra } \\
\text { (D07). }\end{array}$ & 8 & $\begin{array}{c}47,0 \\
5\end{array}$ & 9 & $\begin{array}{c}52,9 \\
4\end{array}$ \\
\hline $\begin{array}{l}\text { 22) Realizar uma pesquisa de } \\
\text { preços para compra de } \\
\text { produtos. }\end{array}$ & $\begin{array}{l}\text { Resolver problemas envolvendo } \\
\text { subtração de números naturais } \\
\text { ou quantias de dinheiro com } \\
\text { resposta exata (D12). }\end{array}$ & 5 & $\begin{array}{c}29,4 \\
1\end{array}$ & 12 & $\begin{array}{c}70,5 \\
9\end{array}$ \\
\hline $\begin{array}{l}\text { 23) Dividir ou distribuir velas } \\
\text { num bolo de aniversário. }\end{array}$ & $\begin{array}{l}\text { Resolver divisão envolvendo } \\
\text { partilha em que o divisor é } \\
\text { número menor que 10. Avalia a } \\
\text { capacidade de dividir em partes } \\
\text { iguais (D14). }\end{array}$ & 6 & $\begin{array}{c}35,2 \\
9\end{array}$ & 11 & $\begin{array}{c}64,7 \\
1\end{array}$ \\
\hline $\begin{array}{l}\text { 24) Simular duas contas em } \\
\text { que dois pedreiros } \\
\text { trabalham juntos, fazendo } \\
\text { uma fileira e retirada de } \\
\text { tijolos. }\end{array}$ & $\begin{array}{l}\text { Reconhecer a ideia de somar e } \\
\text { diminuir. Avalia se o sujeito } \\
\text { planeja para efetuar as ações de } \\
\text { mais de uma operação (D16). }\end{array}$ & 3 & $\begin{array}{c}17,6 \\
5\end{array}$ & 14 & $\begin{array}{c}82,3 \\
5\end{array}$ \\
\hline TOTAL DE RESPOSTAS & & 22 & $\begin{array}{c}32,3 \\
5\end{array}$ & 46 & $\begin{array}{c}67,6 \\
5\end{array}$ \\
\hline
\end{tabular}

Fonte: Produzido pelas autoras a partir da análise da Matriz.

A categoria IV tem por objetivo propor problemas com operações inversas e escrita de números com zero intermediário. Nesta categoria, o percentual de erros foi maior de forma global. Os sujeitos demonstraram déficits na resolução de problemas envolvendo adição e subtração, divisão e multiplicação e adição associadas.

Na questão número 21 emprega-se um endereço em que o sujeito deve anotar o número da rua. Essa questão treina o traçado das letras e a habilidade de desenhar a escrita, e são necessários conhecimentos sobre o sistema decimal. Neste ponto o percentual de acertos foi maior que nas outras questões da categoria, mas inferior a 50\% $(47,05 \%)$.

O artigo sobre aprendizagem e metacognição de Leão et al. (2015) trouxe o paradigma da perspectiva multidisciplinar que necessita ser construída em torno da cognição do adulto, reforçando a ideia da construção de um novo olhar para este tema. É necessário refletir para além do cenário da aprendizagem do adulto, dando atenção à aprendizagem do adulto portador de doença mental.

Nessa perspectiva, Vygotsky (2000) argumenta que a aprendizagem se dá pela mediação do outro e que esta ocorre por meio de instrumentos e signos que permitem o

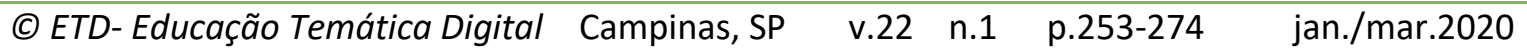


desenvolvimento das faculdades mentais superiores. O desenvolvimento humano, como processo histórico-social, ocorre pela mediação, pois o homem não tem acesso direto aos objetos, mas acesso mediado, por meio de recortes do real, operados pelos sistemas simbólicos de que dispõe.

\section{CONCLUSÃO}

Identificaram-se importantes impactos cognitivos no grupo de portadores de esquizofrenia. Os déficits cognitivos podem ser em razão da regressão sintomática da doença ou da base dos conceitos que, durante a infância, não produziram a significação suficiente para armazenar na memória o conceito, pois, segundo Vygotsky (1994), na esquizofrenia ocorre o oposto do que acontece na adolescência, ou seja, o sujeito com esquizofrenia não consegue formar o verdadeiro conceito, desenvolvendo apenas o pensamento por complexos (pseudoconceitos). As dificuldades foram encontradas em todos os sujeitos, considerando que, conforme o grau de dificuldade de cada questão, foi se ampliando progressivamente o número de erros.

Na categoria I, que apresentou questões simples, a maioria dos sujeitos mostrou ter certo domínio, pois $62,74 \%$ sabem realizar contagens simples e ler números; mesmo assim, somente $35,29 \%$ dos sujeitos conseguiram associar o número ao seu nome, como no caso da dificuldade em reconhecer o número de um ônibus, fator fundamental para autonomia na mobilidade. A categoria II indicou maior número de erros nas operações de subtração, com apenas $29,41 \%$ de acertos em relação às operações de adição, com 52,94\% de acertos. Já as questões que trataram de realizar a comparação de números tiveram um maior número de acertos (70,59\%). Na categoria III os sujeitos demonstraram capacidade de ler números (64,70\%), entretanto mostraram índices significativos de erros em resolver problemas envolvendo multiplicação ou problemas com mais de uma operação (adição e multiplicação; adição e subtração). A categoria IV expressa a incapacidade de escrita e raciocínio lógicomatemático, indicando quase que completa dependência na solução de questões básicas fundamentais do cotidiano. O percentual de erros foi maior de forma global, com apenas $32,35 \%$ de acertos. Os resultados encontrados na investigação demonstram que, consoante as questões propostas aos sujeitos foram se complexificando, o percentual de erros foi aumentando, com 37,26\% (categoria I), 53,68\% (categoria II), 60,78\% (categoria III) e 67,65\% (categoria IV), o que indica a baixa capacidade de formação de conceitos, corroborando as elaborações de Vygotsky.

Considerando que a formação de conceitos é construída de forma relacional a partir do outro, é fundamental que sejam propiciados espaços e tempos de interação e mediação com atividades que promovam o desenvolvimento do pensamento lógico-matemático desses sujeitos, desde atividades simples, como as propostas na categoria I, até as mais complexas, como na categoria IV. Podemos afirmar que o instrumento utilizado para identificar os 
principais déficits cognitivos matemáticos em sujeitos com diagnóstico de esquizofrenia, conforme matriz de referência do Programa Brasil Alfabetizado, caracterizou-se como uma estratégia importante para planejar ações que favoreçam o reestabelecimento (Recovery) de fatores cognitivos básicos que influenciam nas atividades cotidianas dos sujeitos, tanto no âmbito familiar quanto no social, pois, na medida em que o sujeito ouve a palavra em diferentes contextos, mais dia ou menos dia poderá produzir significados mais complexos.

As interações são fundamentais para o desenvolvimento da zona de desenvolvimento proximal do sujeito, por isso sugere-se investigações que acompanhem o processo de desenvolvimento do raciocínio lógico matemático, considerando o impacto na autonomia e na qualidade de vida desses sujeitos e seus familiares.

\section{REFERÊNCIAS}

AGOSTINI, Andreia et al. Beleza e plasticomania. Ries Caçador, v. 2, n. 2, p. 179-184, 2013.

BAMBO, Arsénio Filipe José. Tradução, adaptação cultural e validação para população portuguesa das escalas de avaliação da perturbação formal do pensamento na esquizofrenia. 2010. Dissertação (Mestrado em Psiquiatria e Saúde Mental) - Universidade do Porto, Porto, Portugal, 2010.

BRASIL. Ministério da Saúde. Fundo Nacional da Saúde. Manual [de] ajuda e suporte mútuos em saúde mental: para facilitadores, trabalhadores e profissionais de saúde e saúde mental. Coordenação Eduardo Mourão Vasconcelos. 2013. Disponível em:

http://www.redecaps.org. Acesso em: mar. 2015

BRASIL. Ministério da Educação. Programa Brasil Alfabetizado. Centro de Alfabetização Leitura e Escrita (Ceale). Matriz de Referência Comentada/Matemática/Leitura e Escrita. Brasília: MEC, 2008a.

BRASIL. Ministério da Educação. Programa Brasil Alfabetizado. Centro de Alfabetização Leitura e Escrita (Ceale). Manual do aplicador. Brasília: MEC, 2008b.

BRASIL. Ministério da Educação. Programa Brasil Alfabetizado. Centro de Alfabetização Leitura e Escrita (Ceale). Gabarito comentado. Brasília: MEC, 2008c.

BRASIL. CNS/MS. Conselho Nacional de Saúde, Ministério da Saúde. Resolução 2012. 2012. Disponível em: http://conselho.saude.gov.br/resolucoes/2012/Reso466.pdf. Acesso em: mar. 2015.

COSTA, Eduardo Moura da; PERES, Savio Passafaro. Princípios fenomenológicos da compreensão da esquizofrenia fundamentados em Vigotski. Arquivos Brasileiros de Psicologia, Rio de Janeiro, v.70, n.3, p.128-147, 2018.

FERREIRA JUNIOR, Breno de Castro et al. Alterações cognitivas na esquizofrenia: atualização. Revista de Psiquiatria do Rio Grande do Sul, v.32, n.2, p. 57-63, 2010. 
FREIRE, Paulo. Pedagogia da autonomia: saberes necessários à prática educativa. São Paulo: Paz e Terra, 1996-2002.

GIACON, Bianca Cristina Ciccone; GALERA, Sueli Aparecida Frari. Ajustamento familiar após o surgimento da esquizofrenia. Revista Brasileira de Enfermagem, Brasília, v.66, n.3, p. 321326, maio/jun. 2013.

HÜBNER, Carlos Von Krakauer; KAIROF MARI, Renata Novelli; COELHO, Hadassa Hossri Faria. Esquizofrenia e transtorno psicótico induzido por substâncias, uma difícil distinção. Revista da Faculdade de Ciências Médicas de Sorocaba, v. 20, Supl., out. 2018. (Congresso da SUMEP, 35.).

LEÃO, Marluce Auxiliadora Borges Glaus et al. Aprendizagem e metacognição do adulto: panorama de estudos e pesquisas. Ciências \& Cognição, v. 20. n.1, p. 133-141, 2015.

MARQUES-TEIXEIRA, João. A esquizofrenia. Updates, v.3, n. 2, mar. /abr. 2015.

MARTINS, Angela Maria. Autonomia e educação: a trajetória de um conceito. Cadernos de Pesquisa, Fundação Carlos Chagas, n. 115, p. 207-232, mar. 2002.

MATTOS, Rafael da Silva. Muito mais do que um dicionário do corpo: um dicionário para o corpo. Physis Revista de Saúde Coletiva, Rio de Janeiro, v.23, n.1, p. 285-288, 2013.

MELO, Juliana Rízia Félix de et al. Escala de benevolência frente à esquizofrenia: construção e evidências de validação. Estud. Psicol., Campinas, v. 36, 2019.

PLAZA, María Eugenia Nieva. Sistematización de la Práctica Supervisada Realizada en Casa Club Bien Estar “Esquizofrenia y Déficit Cognitivo". Tese. Universidade Nacional de Córdoba, Faculdade de Psicologia, Córdoba, 2010.

ROCHA, N. et al. Relação entre Neurocognição e Qualidade de Vida em Pessoas com Esquizofrenia. Acta Medica Portuguesa, v.22, p. 71-82, 2009.

SÁ, Andreia Ferreira de. Cognição e esquizofrenia: estudo neuropsicológico para discriminação dos domínios cognitivos mais afetados. 2011. Dissertação (Mestrado Integrado de Psicologia) - Universidade do Porto, Faculdade de Psicologia e de Ciências da Educação, Portugal, 2011.

SÁNCHEZ, Hugo Selma. Rehabilitación cognitiva en la esquizofrenia. Psicologia, Conocimiento y Sociedad, v. 2 n.1, p. 80-129, mayo 2012.

SILVA, Regina Cláudia Barbosa da. Esquizofrenia: uma revisão. Psicologia USP, Universidade Federal de São Paulo - Unifesp, v.17, n.4, p. 263-285, 2006.

STERIAN, Alexandra. Esquizofrenia. São Paulo: Casa do Psicólogo, 2001.

VAZ-SERRA, Adriano et al. Cognição, cognição social e funcionalidade na esquizofrenia. Acta Médica Portuguesa, v.23, p. 1.043-1.058, 2010.

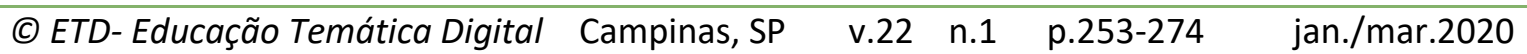


VYGOTSKY, Lev Semyonovich. Pensamento e linguagem. 4. ed. São Paulo: Martins Fontes, 2013.

VYGOTSKY, Lev Semyonovich. Thought in schizophrenia. In: VALSINER, Jaan; VAN DER VEER, Rene (Ed.). The Vygotsky reader. Oxford, UK; Cambridge USA: Basil Blackwell, 1994. p. 313326.

VYGOTSKY, Lev Semyonovich. A construção do pensamento e da linguagem. São Paulo: Martins Fontes, 2000.

\section{Revisão gramatical realizada por:}

Ana Basso Andrigheto.

E-mail: denise@unijui.edu.br 